\title{
Community-Acquired Respiratory Viruses in Oncology: Lessons to Be Learnt from the SARS-CoV-2 Pandemic
}

\author{
Marie von Lilienfeld-Toal ${ }^{a, b}$ \\ ${ }^{a}$ Abteilung für Hämatologie und internistische Onkologie, Klinik für Innere Medizin II, Universitätsklinikum Jena,

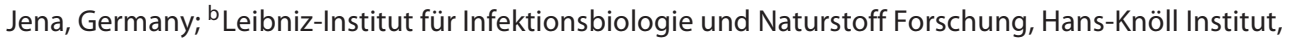 \\ Jena, Germany
}

As a hematologist with an interest in infectious diseases I would like to use this opportunity to repeat a long-standing message: community-acquired respiratory viruses (CARV) are potential killers, especially for cancer patients [1]. Influenza has long been famous for causing seasonal excess mortality in all populations and is therefore well known as a dangerous pathogen in cancer patients in particular $[2,3]$. Other CARV with complicated names such as respiratory syncytial virus (RSV), parainfluenza, or human metapneumovirus (hMPV) have also been described as causes of pneumonia with high fatality rates in patients with hematological malignancies inside and outside the transplant setting [4-6]. It seems that shortly after the novel description of a respiratory virus oncologists have previously never heard of, there is the report of an outbreak, sometimes with fatal consequences, on a hematology/oncology unit somewhere on the globe $[4,5,7]$. So why should this be any different for SARS-CoV-2? The characteristics are the same, albeit probably aggravated, as for the other CARV: firstly, an infection with SARS-CoV-2 is per se potentially dangerous, secondly, the virus is highly contagious and has a high potential for nosocomial transmission, and lastly, clinicians are not used to and thus not sufficiently aware of this particular pathogen.

In this issue of Oncology Research and Treatment, there is the report of an outbreak of SARS-CoV-2 on a hematology unit together with the description of its successful containment along with a review of a possible strategy to manage care for cancer patients in times of COVID-19. There are several lessons to be learnt from this valuable report:

Outbreaks with CARV happen, and they happen to anyone, even to units of the highest standards.

Outbreaks with CARV need to be recognized quickly, and effective measures need to be taken rapidly, although they may appear radical at times.

If dealt with appropriately, outbreaks can be contained, and cancer care can be ensured at the highest possible standard even in times of a pandemic.

The most important resource to continue cancer care in the situation of a pandemic is enough dedicated staff.

So, what does it take to make sure all cancer patients receive optimal therapy during the COVID-19 crisis? We need to take the virus and the disease it causes absolutely seriously. We need to find the right balance between implementing appropriate precautions on the one hand and causing collateral damage by denying cancer patients the tumor therapy they need on the other hand. Recommendations should be as rational and evidence-based as possible (as they usually are in cancer care). For this, high-quality evidence needs to be gathered as quickly as possible, and the development of recommendations even in times of crisis should be consensus-based with critical appraisal. The aim is to care for our patients as safely and as effectively as we usually do, which has led to the well-described increase in survival and quality of life in the recent years $[8,9]$.

In my impression, this is exactly what the community of hematologists and oncologists has been striving for with an immense effort over the past weeks. All clinicians and healthcare workers involved in either treating COVID-19 patients or working hard to compensate potential implications on routine cancer care cannot be thanked enough. 
If the efforts of everyone involved are recognized and the lessons learnt from the SARS-CoV-2 pandemic kept in mind, the community is well prepared for any other upcoming crisis, including safe management of the yearly mini-crisis of seasonal CARV epidemics.

\section{Disclosure Statement}

Honoraria/consulting fees: Celgene, Janssen, Takeda, Amgen, Oncopeptides, Cancer Drug Development Forum, Gilead, Merck, and BMS. Research funding: Celgene, Gilead, Novartis, and Deutsche Krebshilfe.

\section{References}

1 von Lilienfeld-Toal M, Maschmeyer G. Challenges in Infectious Diseases for Haematologists. Oncol Res Treat. 2018;41(6):406-10.

2 Ljungman P, de la Camara R, Perez-Bercoff L, Abecasis M, Nieto Campuzano JB, CannataOrtiz MJ, et al.; Infectious Diseases Working Party, European Group for Blood and Marrow Transplantation; Infectious Complications Subcommittee, Spanish Group of Haematopoietic Stem-cell Transplantation. Outcome of pandemic H1N1 infections in hematopoietic stem cell transplant recipients. Haematologica. 2011 Aug;96(8):1231-5.

3 Chemaly RF, Vigil KJ, Saad M, Vilar-Compte D, Cornejo-Juarez P, Perez-Jimenez C, et al. A multicenter study of pandemic influenza A (H1N1) infection in patients with solid tumors in 3 countries: early therapy improves outcomes. Cancer. 2012 Sep;118(18):4627-33.
4 Sydnor ER, Greer A, Budd AP, Pehar M, Munshaw S, Neofytos D, et al. An outbreak of human parainfluenza virus 3 infection in an outpatient hematopoietic stem cell transplantation clinic. Am J Infect Control. 2012 Sep; 40(7):601-5.

5 Lehners N, Schnitzler P, Geis S, Puthenparambil J, Benz MA, Alber B, et al. Risk factors and containment of respiratory syncytial virus outbreak in a hematology and transplant unit. Bone Marrow Transplant. 2013 Nov;48(12):1548-53.

6 Spahr Y, Tschudin-Sutter S, Baettig V, Compagno F, Tamm M, Halter J, et al. Community-Acquired Respiratory Paramyxovirus Infection After Allogeneic Hematopoietic Cell Transplantation: A Single-Center Experience. Open Forum Infect Dis. 2018 Apr; 5(5):ofy077.
7 Kim S, Sung H, Im HJ, Hong SJ, Kim MN. Molecular epidemiological investigation of a nosocomial outbreak of human metapneumovirus infection in a pediatric hemato-oncology patient population. J Clin Microbiol. 2009 Apr;47(4):1221-4.

8 Arnold M, Rutherford MJ, Bardot A, Ferlay J, Andersson TM, Myklebust TA, et al. Progress in cancer survival, mortality, and incidence in seven high-income countries 1995-2014 (ICBP SURVMARK-2): a population-based study. Lancet Oncol. 2019 Nov;20(11):1493505.

9 Carioli G, Bertuccio P, Boffetta P, Levi F, La Vecchia C, Negri E, et al. European cancer mortality predictions for the year 2020 with a focus on prostate cancer. Ann Oncol. 2020 May;31(5):650-8. 